\title{
Resposta do amendoinzeiro a diferentes fontes e doses de fósforo
}

\author{
Peanut response to different sources and doses of phosphorus
}

Respuesta del maní a diferentes fuentes y dosis de fósforo

Recebido: 30/09/2021 | Revisado: 09/10/2021 | Aceito: 11/10/2021 | Publicado: 12/10/2021

Thais Cardoso de Souza

ORCID: https://orcid.org/0000-0003-4435-6183 Instituto Federal de Educação, Ciência e Tecnologia do Norte de Minas Gerais, Brasil E-mail: thaiscardosoifnmg@gmail.com

Francisco Valdevino Bezerra Neto

ORCID: http://orcid.org/0000-0002-8878-6786 Instituto Federal de Educação, Ciência e Tecnologia do Norte de Minas Gerais, Brasil E-mail: francisco.neto@ifnmg.edu.br

Maria Ângela Cruz Macêdo dos Santos

ORCID: https://orcid.org/0000-0003-1418-7438 Instituto Federal de Educação, Ciência e Tecnologia do Norte de Minas Gerais, Brasil E-mail: angela_macedo.08@hotmail.com

Alisson Macendo Amaral

ORCID: https://orcid.org/0000-0003-3035-2763 Instituto Federal de Educação, Ciência e Tecnologia do Norte de Minas Gerais, Brasil E-mail: alisson.amaral@ifnmg.edu.br

\begin{abstract}
Resumo
No Brasil a produção de amendoim cresce anualmente. No estado de Minas Gerais para alcançar a produtividade da cultura, o investimento nutricional é primordial e um dos nutrientes principais para o desenvolvimento do amendoim é o fósforo. Devido à escassez de informações de produção de amendoinzeiro no Cerrado Mineiro, o experimento objetivou avaliar a influência de doses e fontes de fósforo no amendoinzeiro. O delineamento estatístico utilizado foi o de blocos ao acaso (DBC), distribuído em dois esquemas fatoriais, um sendo $5 \times 2 \times 6$ (doses $\times$ fontes $\times$ épocas) durante o desenvolvimento da cultura e o outro $5 \times 2$ (doses $\times$ fontes) no final de ciclo, em época de produção. Os tratamentos foram compostos por 5 doses de fósforo $\left(0,40,80,120,160 \mathrm{Kg} \mathrm{ha}^{-1}\right), 2$ fontes de fósforo (superfosfato simples e superfosfato triplo) e 6 épocas de avaliação $(15,30,45,60,75$ e 95) dias após a emergência. Nos 2 delineamentos houveram 4 repetições. Foram feitas análises de crescimento e produtivas. Com as análises foi possível observar que a fonte superfosfato simples garantiu maior aporte de área foliar e matéria seca, porém na altura de planta (haste) a melhor fonte foi o superfosfato triplo com as doses 40 e $160 \mathrm{~kg} \mathrm{ha}^{-1}$. Devido ao aporte de matéria seca, melhoria estrutural da cultura e um custo $21,51 \%$ menor, concluiu-se que a melhor fonte de fósforo a ser usada é o superfosfato simples.
\end{abstract}

Palavras-chave: Arachis hypogaea L.; Adubação fosfatada; Cerrado Mineiro.

\begin{abstract}
In Brazil, peanut production grows annually. In the state of Minas Gerais, to achieve crop productivity, nutritional investment is essential and one of the main nutrients for peanut development is phosphorus. Due to the scarcity of information on peanut production in the Cerrado Mineiro, the experiment aimed to evaluate the influence of phosphorus doses and sources in the peanut tree. The statistical design used was randomized blocks (DBC), distributed in two factorial schemes, one being 5 × 2 × 6 (doses x sources x evaluon seasons) during crop development and the other $5 \times 2$ (doses $x$ sources) at the end of the cycle, at the time of production. The treatments consisted of 5 phosphorus doses $(0,40,80,120,160 \mathrm{Kg}$ ha-1), 2 phosphorus sources (single superphosphate and triple superphosphate) and 6 evaluation seasons $(15,30,45,60,75$ and 95) days after emergence. In the 2 designs there were 4 repetitions. Growth and yield analyzes were performed. With the analysis it was possible to observe that superphosphate source ensured greater contribution of leaf area and dry matter, but at plant height the best source was triple superphosphate with doses 40 and $160 \mathrm{~kg} \mathrm{ha}^{-1}$. Due to the contribution of dry matter, structural improvement of the culture and a $21.51 \%$ lower cost, it was concluded that the best source of phosphorus to be used is simple superphosphate.
\end{abstract}

Keywords: Arachis hypogaea L.; Phosphate fertilization; Cerrado Mineiro.

\section{Resumen}

En Brasil, la producción de maní crece anualmente. En el estado de Minas Gerais, para lograr la productividad de los cultivos, la inversión nutricional es fundamental y uno de los principales nutrientes para el desarrollo del maní es el 
fósforo. Debido a la escasez de información sobre la producción de maní en el Cerrado Mineiro, el experimento tuvo como objetivo evaluar la influencia de las dosis y fuentes de fósforo en el maní. El diseño estadístico utilizado fue de bloques aleatorios (DBC), distribuidos en dos esquemas factoriales, uno de 5 × 2 × 6 (dosis x fuentes x temporadas) durante el desarrollo del cultivo y el otro 5 x 2 (dosis x fuentes) al final del período. ciclo, en el momento de la producción. Los tratamientos consistieron en 5 dosis de fósforo $(0,40,80,120,160 \mathrm{Kg}$ ha-1), 2 fuentes de fósforo (superfosfato simple y superfosfato triple) y 6 tiempos de evaluación $(15,30,45,60,75$ y 95) días después de la emergencia. En los 2 diseños hubo 4 repeticiones. Se realizaron análisis de crecimiento y rendimiento. Con el análisis se pudo observar que la fuente única de superfosfato aseguró mayor aporte de área foliar y materia seca, pero a la altura de la planta (tallo) la mejor fuente fue el superfosfato triple con dosis de 40 y $160 \mathrm{~kg}$ ha-1. Debido al aporte de materia seca, la mejora estructural del cultivo y un costo $21.51 \%$ menor, se concluyó que la mejor fuente de fósforo a utilizar es el superfosfato simple.

Palabras clave: Arachis hypogaea L.; Fertilización con fosfato; Cerrado Mineiro.

\section{Introdução}

O amendoim (Arachis hypogaea L.) é uma leguminosa originária da América do Sul, cultivada pelos nativos muito antes da chegada dos espanhóis e portugueses no século XV. A semente do amendoim é uma importante fonte de gordura, além de ser uma fonte renovável de energia (Bertioli, et al., 2011; Felippe, 2011). Por ser cultivado principalmente como fonte de proteína vegetal e de óleo, o amendoim tornou-se a segunda leguminosa mais importante no Brasil, sendo que no ano de 2019/2020 (primeira e segunda safras), foi estimada uma produção de 558,4 mil toneladas, ou seja, produção 28,5\% maior que na última safra (2017/2018) (Conab, 2020).

Em 2019, as três cidades com maiores áreas de plantio de amendoim foram Frutal, Santa Vitória e Iturama, todas na região do Triângulo Mineiro, já em 2020, Minas Gerais registrou recorde com um aumento anual na produção com de 14,3 milhões de toneladas (Camilo, 2020; Agência Minas, 2020).

A disponibilidade dos nutrientes para a cultura no solo é fundamental para elevar a produtividade do amendoim, sendo o fósforo um nutriente crucial no metabolismo da planta, favorecendo o crescimento inicial das raízes e desenvolvimento de sementes. Além disso, a adubação fosfatada é imprescindível para a produção agrícola nos solos da região do Cerrado, cuja disponibilidade é naturalmente baixa, sendo um dos investimentos que mais onera a prática da agricultura comercial nas regiões com predominância desse bioma (Embrapa, 2016; Marques, 2014).

No mercado podem ser encontradas muitas fontes de fósforo solúvel, sendo mais comum, o superfosfato triplo e superfosfato simples, que apresentam vantagens da rápida disponibilidade dos nutrientes para as plantas, entretanto, apresentam a desvantagem de possuir menor efeito residual para a cultura sucessora (Bolonhezi et al, 2005).

Diante do exposto e devido à escassez de informações de produção de amendoinzeiro no Cerrado Mineiro, principalmente na região Norte, são necessários estudos visando elucidar as necessidades da adubação fosfatada, bem como as fontes de fornecimento de fósforo mais adequadas à essa cultura.

\section{Metodologia}

O experimento foi conduzido em ambiente protegido de setembro de 2020 a janeiro de 2021, situado na área experimental do Instituto Federal do Norte de Minas Gerais (IFNMG) - Campus Arinos, com coordenadas de latitude $15^{\circ}$ 55' $\mathrm{S}$, longitude $46^{\circ} 8^{\prime} \mathrm{O}$ e altitude de $525 \mathrm{~m}$. O clima predominante é do tipo Aw (clima tropical com estação seca de inverno). O delineamento estatístico utilizado foi o de blocos ao acaso (DBC), distribuído em dois esquemas fatoriais, um sendo 5 x 2 x 6 (doses $\mathrm{x}$ fontes x épocas) durante o desenvolvimento da cultura e o outro 5 x 2 (doses x fontes) no final de ciclo, em época de produção. Os tratamentos foram compostos por 5 doses de fósforo $\left(0,40,80,120,160 \mathrm{Kg}^{-1}\right), 2$ fontes de fósforo (superfosfato simples e superfosfato triplo) e 6 épocas de avaliação $(15,30,45,60,75$ e 95) dias após a emergência - DAE. Nos 2 delineamentos houveram 4 repetições. A unidade experimental constituiu-se de 1 planta de amendoinzeiro cv Tatu ST 
(IAC) por vaso. As plantas foram semeadas em 44 vasos, sendo 40 para os tratamentos e 4 para os lisímetros, estes últimos usados no manejo da reposição hídrica da cultura. Cada vaso possuía um volume de $25 \mathrm{~L}$, perfazendo em seu interior um elemento filtrante e acima dele, depositado o solo usado para o cultivo.

O elemento filtrante foi composto de $1 \mathrm{~cm}$ de brita $\mathrm{n}^{\circ} 1$, tela do tipo sombrite e $1 \mathrm{~cm}$ de areia lavada, onde foi acomodado um Latossolo Vermelho Distrófico (LVD) proveniente de camada agricultável de área experimental próxima ao ambiente protegido. A correção do solo foi feita por meio de calagem para elevar a saturação por bases para 80\% (Aguiar et al., 2014) por meio da análise de solo (Tabela 1). Foi aplicado calcário dolomítico Filler e posteriormente o solo foi mantido incubado em vasos por 30 dias com umidade acima de $60 \%$ da capacidade de campo. A adubação foi realizada com base na análise de solo para a cultura, convertendo as doses para o volume útil do solo.

Tabela 1. Caracterização química e granulométrica de amostra do Latossolo Vermelho usado no experimento.

\begin{tabular}{|c|c|c|c|c|c|c|c|c|c|c|}
\hline $\mathbf{P h}$ & $\mathbf{P}$ & $\mathbf{K}$ & $\mathrm{Ca}+\mathrm{Mg}$ & $\mathbf{H}+\mathbf{A l}$ & SB & CTC & $\mathbf{V}$ & Areia & Silte & Argila \\
\hline $\mathrm{CCl}_{2}$ & \multicolumn{2}{|c|}{-----mg dm-3---- } & \multicolumn{2}{|c|}{------- cmolc dm dm $^{-3}$} & \multicolumn{3}{|c|}{ 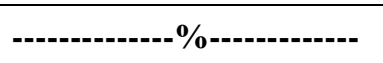 } & \multicolumn{3}{|c|}{ 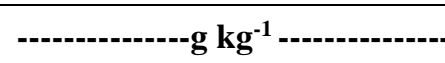 } \\
\hline 4,4 & 11,2 & 71 & 1,83 & 5,50 & 2,01 & 2,32 & 26,8 & 299 & 250 & 451 \\
\hline
\end{tabular}

Fonte: Autores (2021).

Após o preparo dos vasos e correção do solo, realizou-se a semeadura, distribuindo-se 10 sementes por vaso. O desbaste foi feito aos 14 dias após a semeadura (DAS) deixando-se apenas 1 planta por vaso.

Para suprir as necessidade hídrica do amendoinzeiro, as irrigações foram realizadas diariamente por meio de irrigação localizada e manual, perfazendo o uso de uma proveta graduada para reposição da evapotranspiração real da cultura (ETr) a partir de vasos externos que funcionaram como lisímetros de drenagem (Bernardo et al., 2008; Verssiani et al., 2021; Mendes et al., 2020). Para determinação da ETr, utilizou-se 4 vasos com plantas para estimativa da lâmina de irrigação, com isso, a elevação da umidade ocorreu com adição de um volume de água conhecido, suficiente para que ocorresse drenagem. Após ocorrer a drenagem, obtinha-se a lâmina de irrigação pela diferença entre o volume aplicado (VA) e volume drenado (VD), resultando no volume consumido/retido $(\mathrm{VC})$. $\mathrm{O}$ volume médio consumido era reposto às unidades experimentais.

Todos os manejos fitossanitários foram realizados de forma manual de acordo as recomendações para a cultura em estudo (Aguiar et al., 2014). Análises de crescimento foram feitas por meio de métodos não destrutivos, em intervalos quinzenais e compostas por: altura da haste principal (AHP), número de folíolos (NF), número de hastes (NH) diâmetro da haste principal (DHP) e área foliar (AF). Determinou-se AHP com o auxílio de uma régua graduada em centímetros, como a distância compreendida entre a superfície do coleto e a extremidade da haste principal; já o DHP foi mensurado por meio de um paquímetro, tomando como base o coleto da planta. A área foliar foi estimada por método indireto, conforme Equação 1, sugerida por Cardozo et al. (2011). A AF total foi calculada pelo produto da AF média de 9 folíolos e o NF. Os 9 folíolos foram contabilizados pelas medições de 3 folíolos no terço superior, 3 folíolos no terço médio e 3 folíolos no terço inferior.

$\mathrm{AF}=0,7266(\mathrm{CL})$

Em que: $\mathrm{AF}=$ Área foliar, em $\left(\mathrm{cm}^{2}\right) ; \mathrm{C}=$ Comprimento da folha, em $(\mathrm{cm}) ; \mathrm{L}=$ Largura da folha, em $(\mathrm{cm})$.

$\mathrm{O} \mathrm{NF}$ e o NH foram contabilizados, respectivamente, por meio de contagem direta e a determinação da maturação 
completa dos legumes, registrada quando a maioria dos frutos apresentaram coloração marrom na face interna das cascas e quando as sementes apresentaram coloração da película avermelhada, coincidindo aos 95 dias após a semeadura para todos os genótipos (Almeida et al., 2014).

Na colheita, foram feitas análises de fitomassa aos 95 DAE, sendo elas a massa de grãos com casca (MGC) e a massa de grãos sem casca (MGSC). Também foram realizadas análises de rendimento que consistiram no número de vagens por planta (NVP) e número de grãos por vagem (NGV). A produtividade líquida da parte aérea, que representa o acúmulo de fotoassimilados na parte aérea da planta, foram calculados pela razão da diferença entre a massa seca de caule e folha (MSC e MSF) aos 15 e 95 DAE e a massa seca total (MST) da parte aérea aos 95 DAE. As massas secas aos 15 DAE foram obtidas com as plantas do desbaste. As fitomassas ou massas secas, foram determinadas por pesagem em balança com resolução de $0,001 \mathrm{~g}$ após secagem por 72 horas a $65^{\circ}$ em estufa com ventilação forçada de ar.

Os dados foram tabulados e submetidos à análise de variância pelo teste $\mathrm{F}$ e, quando significativos, as médias dos fatores qualitativos foram analisados pelo teste de Tukey a 5\% de probabilidade e os efeitos das variáveis quantitativas por meio de análise de regressão com auxílio do software estatístico SISVAR versão 5.6 (Ferreira, 2014). Gráficos e figuras foram gerados com auxílio das ferramentas computacionais Excel e SigmaPlot, v.11, para melhor visualização e entendimento dos resultados. Ademais, todos os princípios e rigores metodológicos e científicos estão de acordo com (Pereira et al., 2018; Koche, 2011).

\section{Resultados e discussão}

Pela Tabela 2, observa-se que houve efeito significativo das épocas de avaliação na AHP e interação entre os fatores fonte e dose. Para DHP houve efeito significativo do fator época, já para NF observou-se significância nos fatores dose e época. Para AF houve significância nos fatores dose e época, havendo interação entre fonte e época (Tabela 2).

Tabela 2. Síntese da análise de variância para as variáveis AHP, NF, DHP, AF, NH.

\begin{tabular}{|c|c|c|c|c|c|c|}
\hline \multirow{2}{*}{ Fonte de variação } & \multirow{2}{*}{ GL } & \multicolumn{5}{|c|}{ Quadrados médios } \\
\hline & & Altura $^{1}$ & Diâmetro $^{1}$ & N. Folíolos ${ }^{1}$ & A. Foliar ${ }^{2}$ & N. Hastes ${ }^{1}$ \\
\hline Bloco & 3 & $528,42 * *$ & $0,04^{\mathrm{ns}}$ & $111,62 * *$ & $0,11 * *$ & $26,23 * *$ \\
\hline Fonte $(\mathrm{F})$ & 1 & $0,66^{\mathrm{ns}}$ & $0,05^{\mathrm{ns}}$ & $48,54^{\mathrm{ns}}$ & $0,02^{\mathrm{ns}}$ & $12,56^{\mathrm{ns}}$ \\
\hline Dose (D) & 4 & $80,21 *$ & $0.04^{\mathrm{ns}}$ & $139,45^{* *}$ & $0,08 * *$ & $34,62 * *$ \\
\hline Época (E) & 4 & $5335,99 * *$ & $29,02 * *$ & $7435,21 * *$ & $14,96 * *$ & $1845,48 * *$ \\
\hline$F \times D$ & 4 & $159,13 * *$ & $0,01^{\mathrm{ns}}$ & $30,71^{\mathrm{ns}}$ & $0,01^{\mathrm{ns}}$ & $7,75^{\mathrm{ns}}$ \\
\hline $\mathrm{F} \times \mathrm{E}$ & 4 & $13,38^{\mathrm{ns}}$ & $0,02^{\mathrm{ns}}$ & $3,24^{\mathrm{ns}}$ & $0,05^{*}$ & $0,80^{\mathrm{ns}}$ \\
\hline $\mathrm{D} \times \mathrm{E}$ & 16 & $14,26^{\mathrm{ns}}$ & $0,02^{\mathrm{ns}}$ & $14,56^{\mathrm{ns}}$ & $0.02^{\mathrm{ns}}$ & $3,58^{\mathrm{ns}}$ \\
\hline$F \times D \times E$ & 16 & $24,72^{\mathrm{ns}}$ & $0,02^{\mathrm{ns}}$ & $5,02^{\mathrm{ns}}$ & $0,00^{\mathrm{ns}}$ & $1,34^{\mathrm{ns}}$ \\
\hline Resíduo & 147 & 25,81 & 0,03 & 14,42 & 0,01 & 3,62 \\
\hline $\mathrm{CV}(\%)$ & & 11,38 & 7,10 & 12,90 & 3,59 & 12,89 \\
\hline Média (Fonte) & & 44,66 & & & & \\
\hline
\end{tabular}

GL - Grau de liberdade; QM - Quadrado médio; ** - Significativo ao nível de 1\% de probabilidade; * - Significativo a 5\% de probabilidade; CV $(\%)$ - Coeficiente de variação; ${ }^{1}-\sqrt{(x+1)} ;^{2}-\log Y$. Fonte: Autores (2021).

Seguindo um modelo quadrático, o número de hastes e folíolos foram influenciados pela dose (Figura 1). As doses testadas foram inferiores ao ponto máximo obtido pelas curvas, dessa forma para que se obtenha o número máximo de folíolos 
$(\sim 1223,0)$ deve ser utilizada uma dose $240 \mathrm{~kg} \mathrm{ha}^{-1}$, seja de superfosfato triplo ou superfosfato simples, onde ocorre o mesmo para o número máximo de hastes $(\sim 305,0)$ utilizando-se a dose de $235,0 \mathrm{~kg} \mathrm{ha}^{-1}$.

Figura 1. Variáveis NF (a) e NH (b) em relação as doses aplicadas para esse experimento
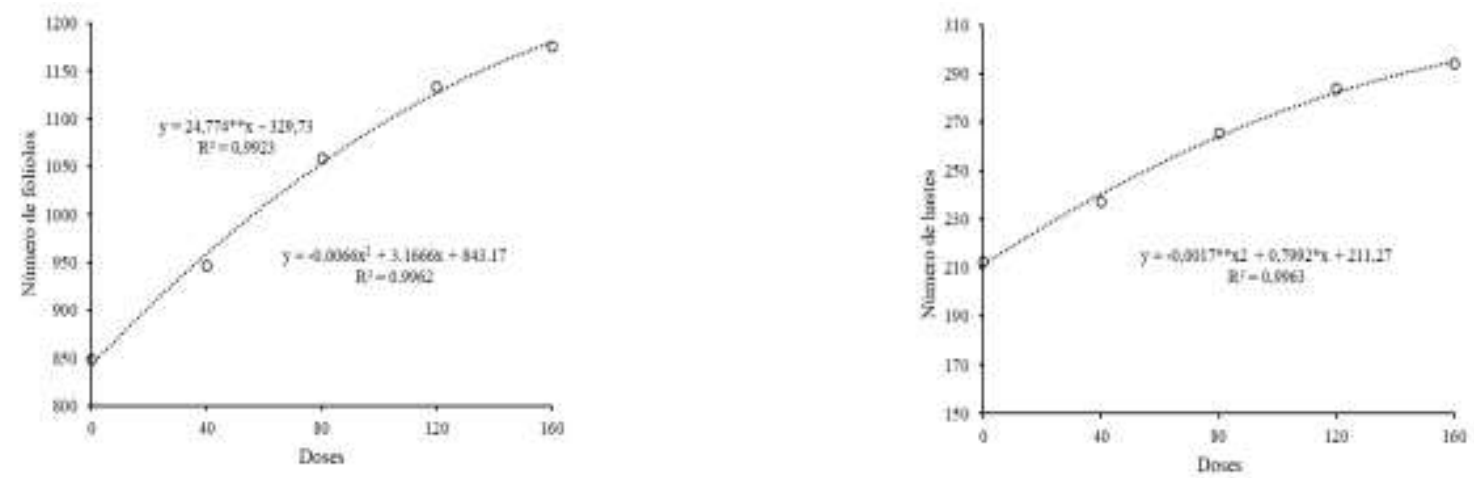

(a)

Fonte: Autores (2021).

Em relação às épocas de avaliação, a maior altura de haste (AHP) ocorreu aos 84 DAE com 54,27 cm e aos 86 DAE a planta atingiu seu diâmetro máximo de 9,43 mm (Figura 2). Observa-se que, uma vez que ocorrem os pontos máximos de AHP e DHP, o crescimento nessas variáveis são cessados, porém, a cultura segue o ciclo investindo em produção de NH e NF (Figura 3) de forma linear. Isso ocorre devido à manutenção da área foliar no período reprodutivo, cujas plantas nessa fase demandam grande quantidade de energia, esta direcionada para a produção de ginóforos e também ao crescimento indeterminado (Nogueira et al., 2013).

Figura 2. Variáveis DH (a), AH (b).
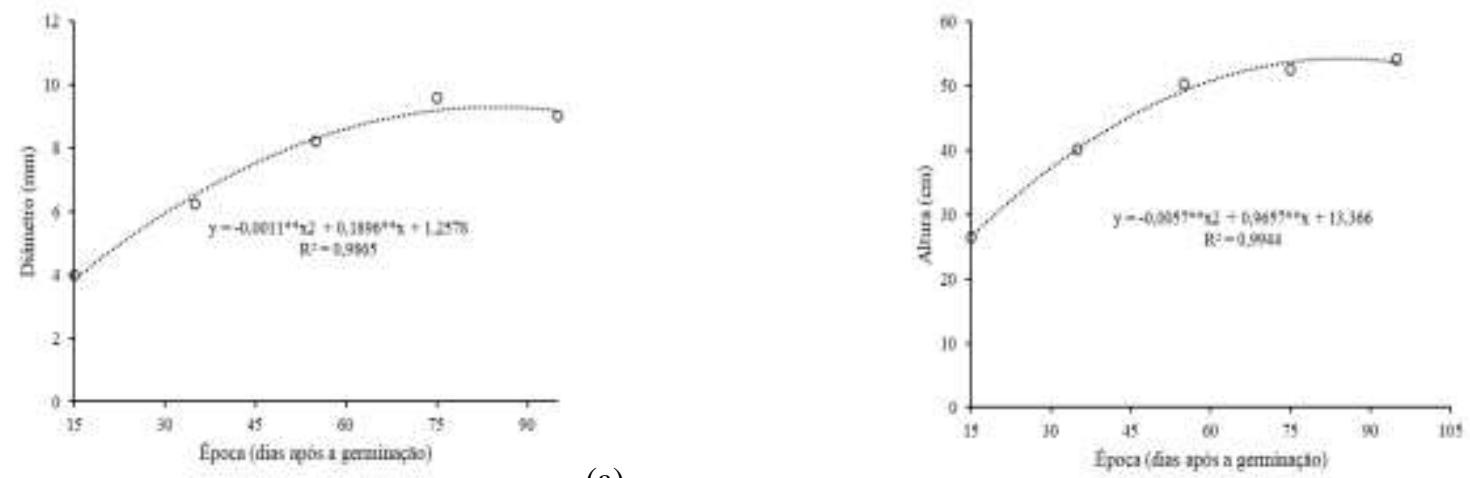

(a)

Fonte: Autores (2021). 
Figura 3. $\mathrm{NF}(\mathrm{a})$ e $\mathrm{NH}(\mathrm{b})$ em relação à época (dias após a geminação).

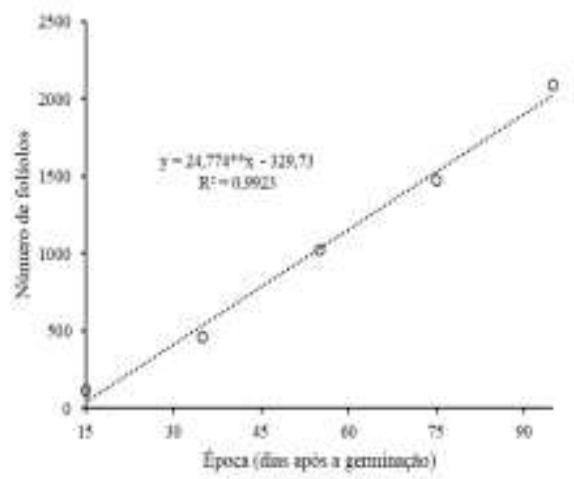

(a)

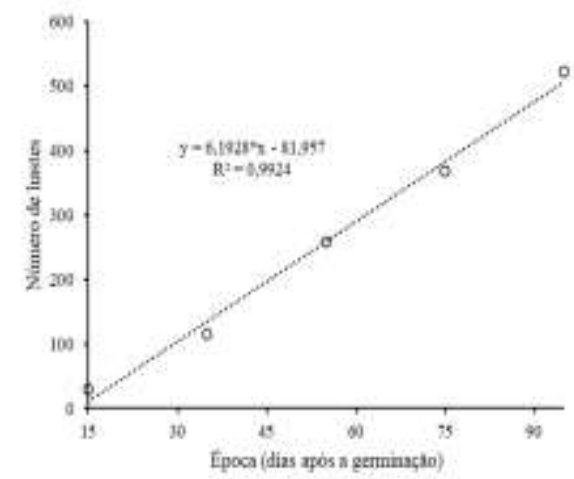

(b)

Fonte: Autores (2021).

Em relação à significância do fator dose na altura de planta (Figura 4), observa-se que a área foliar máxima ocorre com uma dose de $182,77 \mathrm{Kg} \mathrm{ha}^{-1}$ obtendo-se um valor 19.622,05 $\mathrm{cm}^{2}$, ambos determinados pela expressão de ajuste.

Figura 4. Área foliar em relação à dose.

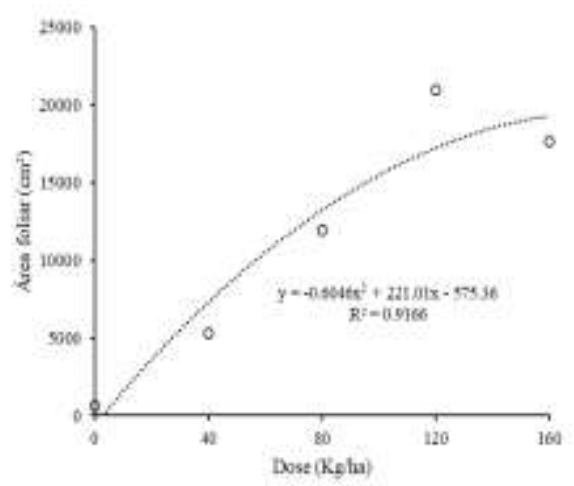

Fonte: Autores (2021).

Na Tabela 3 observa-se o desdobramento da fonte dentro da dose. Na dose 0 a planta obteve 47,18 cm de altura com a fonte superfosfato simples, ou seja, 8,98\% maior quando usado o superfosfato triplo. Já para a fonte superfosfato triplo as doses 40 e 160 proporcionaram uma altura de 47,88 cm e 46,65 cm, respectivamente 12, 26\% e 7,68\% maiores do que os valores encontrado com o uso do superfosfato simples.

Tabela 3. Desdobramento de fonte dentro de cada dose, para a variável altura da planta (AHP)

\begin{tabular}{crcc}
\hline \multirow{2}{*}{ Fonte } & \multicolumn{3}{c}{ Dose $\left(\mathrm{Kg} \mathrm{ha}^{-1}\right)$} \\
\cline { 2 - 4 } & 0 & 40 & 160 \\
\hline Superfosfato Simples & $47,18 \mathrm{a}$ & $42,65 \mathrm{~b}$ & $43,51 \mathrm{~b}$ \\
Superfosfato Triplo & $42,94 \mathrm{~b}$ & $47,88 \mathrm{a}$ & $46,85 \mathrm{a}$ \\
\hline
\end{tabular}

Letras iguais na coluna não se diferenciam por Tukey a $5 \%$ de probabilidade. Fonte: Autores (2021). 
Em um experimento conduzido por Souza et al, (2012) onde foi avaliado o desempenho do amendoim rasteiro em resposta à adubação fosfatada utilizando-se o superfosfato triplo, os autores verificaram comportamento linear e significativo para a altura das plantas. Para o desdobramento da dose dentro de cada fonte não houve ajuste estatístico, logo não foi discutido nesse trabalho.

De acordo a Tabela 4 houve uma significância de AF da cultura aos 75 DAE, com maior média observada usando o superfosfato simples. Esse resultado diverge de Alvarez et al. (2005), onde obtiveram com a mesma variedade (cv Tatu) e fonte (superfosfato simples) valores ligeiramente maiores de área foliar entre os dias 14 a 28 DAE. Essa significância de AF aos 75 DAE se deve principalmente à composição desta fonte, possibilitando o fornecimento de cálcio e enxofre e contribuindo para o aprofundamento das raízes, resistência do ginóforo (alongamento do eixo floral), tamanho das sementes e também enchimento e formação das vagens (Bolonhezi et al., 2005). Os efeitos da disponibilidade de cálcio e enxofre, bem como suas melhorias na cultura, já citadas, explicam o comportamento da AF na Figura 5.

Na figura 7, considerando-se o desdobramento da fonte dentro de época, para a variável AF, observa-se que um notório crescimento dessa variável a partir dos 30 DAE, na fonte superfosfato simples em relação ao aumento proporcionado pelo superfosfato triplo.

Tabela 4. Desdobramento de fonte dentro de época para área foliar.

\begin{tabular}{cc}
\hline Fonte & 75 dias \\
\hline Superfosfato Simples & $26709,27 \mathrm{a}$ \\
Superfosfato Triplo & $15210,256 \mathrm{~b}$ \\
\hline
\end{tabular}

Letras iguais na coluna não se diferenciam por Tukey a $5 \%$ de probabilidade. Fonte: Autores (2021).

Figura 5. Variável área foliar (AF) em relação a época para as fontes superfosfato simples e superfosfato triplo.

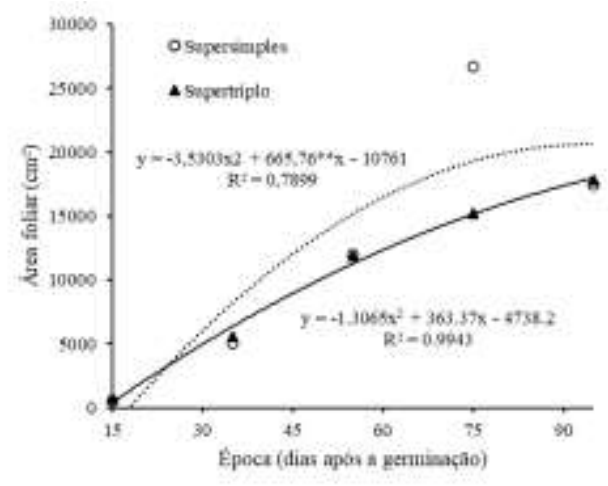

Fonte: Autores (2021).

Não houve influência de fonte e dose nas variáveis NV, NSemV, MVCSem e Msem, porém houve interação desses fatores para a Mseca (Tabela 5). Dessa forma independente da fonte e dose utilizada na adubação fosfatada, a média do número de vagens (NV) será 45,12 vagens, o número de sementes sem vagem (NSV) será 78,57 por planta, a massa verde com sementes (MVCS) será de 207,3 g e a massa de sementes (Msem) será 37,55 g. 
Tabela 5. Síntese da análise de variância e do teste de média para NV, NSV, MVCS, MS, MST.

\begin{tabular}{|c|c|c|c|c|c|c|}
\hline \multirow{2}{*}{ Fonte de variação } & \multirow{2}{*}{ GL } & \multicolumn{5}{|c|}{ Quadrados Médios } \\
\hline & & $\mathrm{NV}^{1}$ & $\mathrm{NSemV}^{1}$ & MVCSem $^{1}$ & Msem $^{1}$ & Mseca $^{1}$ \\
\hline Bloco & 3 & $0,15^{* *}$ & $0,39 * *$ & $1,01 * *$ & $0,41 * *$ & $0,02 * *$ \\
\hline Fonte $(\mathrm{F})$ & 1 & $0,00^{\mathrm{ns}}$ & $0,01^{\mathrm{ns}}$ & $0,00^{\mathrm{ns}}$ & $0,00^{\mathrm{ns}}$ & $0,01^{\mathrm{ns}}$ \\
\hline Dose (D) & 4 & $0,08^{\mathrm{ns}}$ & $0,13^{\mathrm{ns}}$ & $0,02^{\mathrm{ns}}$ & $0,14^{\mathrm{ns}}$ & $0,01^{\mathrm{ns}}$ \\
\hline F x D & 4 & $0,07^{\mathrm{ns}}$ & $0,10^{\mathrm{ns}}$ & $0,01^{\mathrm{ns}}$ & $0,10^{\mathrm{ns}}$ & $0,04 *$ \\
\hline Resíduo & 27 & 0,03 & 0,05 & 0,02 & 0,07 & 0,01 \\
\hline $\mathrm{CV}(\%)$ & & 10,92 & 12,63 & 7,51 & 18,11 & $4,96 \%$ \\
\hline Média - Fontes & & 45,12 & 78,57 & 207,3 & 37,55 & 166,2 \\
\hline
\end{tabular}

GL - Grau de liberdade; QM - Quadrado médio; ** - Significativo ao nível de 1\% de probabilidade; * - Significativo a 5\% de probabilidade; CV (\%) - Coeficiente de variação; $1-\sqrt{(x+1)}: 2-\log$ Y. Fonte: Autores (2021).

De acordo a Tabela 6, nota-se que a fonte superfosfato simples favoreceu um maior aporte de matéria seca apenas na dose de $40 \mathrm{~kg} \mathrm{ha}^{-1}$. Esse trabalho difere de Perin (2001), trabalhando com amendoim-forrageiro cultivado em Argissolo vermelho-amarelo, que demonstrou que essa cultura tolera solos deficientes em fósforo, visto que não houve resposta à adubação de $45 \mathrm{~kg} \mathrm{ha}^{-1}$ de $\mathrm{P}$ (superfosfato triplo) em ocasião do plantio, não tendo ocorrido elevação da produção de matéria seca.

Magalhães et al (2007), afirma que a área foliar está diretamente relacionada à produção final de massa seca, pois durante o ciclo de desenvolvimento, a planta depende das folhas como órgãos fotossintetizantes e a taxa de crescimento da planta depende tanto da taxa de expansão da área foliar como da taxa de fotossíntese por unidade de área foliar. Por essa discussão, pode-se inferir que a dose de $40 \mathrm{Kg} \mathrm{ha}^{-1}$ de superfosfato simples, favorece um aumento de aproximados $40,80 \%$ de massa seca em relação ao uso do superfosfato triplo.

Tabela 6. Desdobramento de fonte dentro de dose para massa seca (MST).

\begin{tabular}{cc}
\hline Fonte & Dose $\mathbf{4 0} \mathbf{~ k g ~ h a}^{-\mathbf{1}}$ \\
\hline Superfosfato simples & $202,25 \mathrm{a}$ \\
Superfosfato triplo & $119,75 \mathrm{~b}$ \\
\hline
\end{tabular}

Letras iguais, na coluna, não se diferenciam por Tukey a 5\% de probabilidade. Fonte: Autores (2021)

Na Figura 6, no desdobramento da dose dentro de fonte, houve ajuste apenas para a dose de Superfosfato simples, onde para atingir a maior massa seca da cultura observa-se que é preciso aplicar uma dose de $133,18 \mathrm{~kg}^{-1} \mathrm{da}$ fonte superfosfato simples para chegar em 181,3 g de matéria seca produzida. 
Figura 6. Desdobramento de dose dentro da fonte de superfosfato simples, para a variável massa seca.

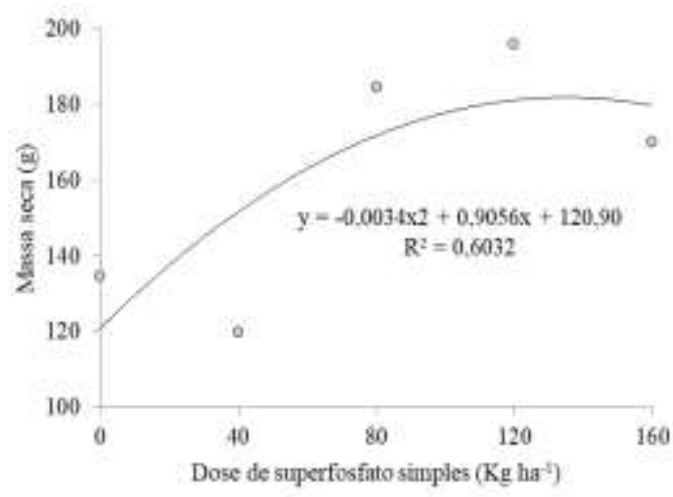

Fonte: Autores (2021).

\section{Conclusão}

A fonte superfosfato simples garantiu maior aporte de AF e MST sendo características de interesse fisiológico da cultura. Para AHP a melhor fonte foi superfosfato triplo com as doses 40 e $160 \mathrm{~kg} \mathrm{ha}^{-1}$.

Levando-se em consideração os fatores de produção, aporte de matéria seca e melhoria estrutural da cultura, nas condições experimentais, observou-se que a melhor fonte de fósforo a ser usada é o superfosfato simples. Além disso, o custo do $\mathrm{Kg}$ dessa fonte, é de 21,51\% menor que o $\mathrm{Kg}$ do fósforo superfosfato triplo.

São necessários mais estudos aplicando mais intervalos de doses de fósforo, para as fontes testadas, com o intuito de definir os limites fisiológicos de crescimento e rendimento do amendoinzeiro cv. Tatu no Cerrado Mineiro.

\section{Agradecimentos}

Os autores agradecem a colaboração de Fabiano José de Campos Bastos, Mestre em Ciências Agrárias e servidor da Companhia Nacional de Abastecimento (CONAB) de Rio Verde - GO.

\section{Referências}

Aguiar, A. T. E., Gonçalves, C., Paterniani, M. E. A. G. Z., Tucci, M. L. S. \& Castro, C. E. F. (2014). Instruções agrícolas para as principais culturas econômicas. Boletim IAC, n. ${ }^{\circ}$ 200. 7 Ed. Instituto Agronômico. https://www.iac.sp.gov.br/publicacoes/arquivos/iacboletim200.pdf

Agência Minas (2020). Safra de amendoim em Minas crescerá quase 50\% neste ano (2019). http://www.agenciaminas.mg.gov.br/noticia/safra-de-amendoimem-minas-crescera-quase-50-neste-anose

Alvarez, R C. F., Rodrigues, J. D., Marubayashi, O. M., Alvarez, A. C. C., Cruscio, C. A. C. et al. (2005). Análise de crescimento de duas cultivares de amendoim (Arachis hypogaea L.). Acta Scientiarum Agronomy, 27(4), 611-6. https://periodicos.uem.br/ojs/index.php/ActaSciAgron/ article/download/1700/1095/

Bernardo, S. \& Soares, A. A.; \& Mantovani, E. C. (2008). Manual de Irrigação. 8 Ed. Editora UFV.

Bertioli, D. J.; Seijo, G.; Freitas, F. O.; Valls, J. F. M.; Bertioli, S. C. M. L.; \& Moretzsohn, M.C. (2011). An overview of peanuts and its wild relatives. Plant Genetic Resources: Characterization and Utilization, 9(1); 134-149. https://doi.org/10.1017/S1479262110000444

Bolonhezi, D.; Pereira, J. C. V. N. A.; Godoy, I. J.; Gentilin Jr., O; \& Freitas, S. S. (2005). Manejo cultural do amendoim. In: O agronegócio do amendoim no Brasil. Editora Embrapa.

Cardozo, N. P.; Parreira, M. C.; Amaral, C. L.; Alves, P. L. C. A.; \& Bianco, S. (2011). Estimativa da área foliar de Crotalaria juncea L. a partir de dimensões lineares do limbo foliar. Bioscience Journal, 27(6), 902-907. http://www.seer.ufu.br/index.php/biosciencejournal/article/view/12123/8115

Camilo, J. V. (2020). Safra de amendoim em Minas crescerá quase 50\% em 2020. http://www.agricultura.mg.gov.br/index.php/component/gmg/story/3727safra-de-amendoim-em-minas-crescera-quase-50-em-2020.

Campanha Nacional de Abastecimento (CONAB). (2020). Acompanhamento da safra brasileira de grãos. Safra 2019/20, 7(9). Brasília-DF. https://www.conab.gov.br/info-agro/safras/graos/boletim-da-safra-de-graos/item/download/32083_394e261c476ea1d66359bed03d095ecb 
Research, Society and Development, v. 10, n. 13, e287101321251, 2021

(CC BY 4.0) | ISSN 2525-3409 | DOI: http://dx.doi.org/10.33448/rsd-v10i13.21251

Empresa Brasileira de Pesquisa Agropecuária (EMBRAPA). (2016). Manejo da adubação fosfatada para culturas anuais no Cerrado. Circular Técnica 33. Embrapa Cerrados. https://ainfo.cnptia.embrapa.br/digital/bitstream/item/154889/1/CT-33.pdf

Felippe, G. (2011). Amendoim: história, botânica e culinária. 1 Ed. Editora Senac.

Koche, J. C. (2011). Fundamentos de metodologia científica. Petrópolis: Vozes. http://www.adm.ufrpe.br/sites/ww4.deinfo.ufrpe.br/ files/Fundamentos_de_Metodologia_Cienti\%CC\%81fica.pdf

Magalhães, P. C.; Durães F. O. M.; \& Rodrigues, J. A. S. Ecofisiologia. In: Rodrigues, J. A. S. (2007). Cultivo do sorgo. 5 Ed. Embrapa Milho e Sorgo.

Marques, D. J; Bianchini, H. C.; \& Roewer L. A. (2014) Fosfito de potássio contribui para enchimento de grãos. https://revistacampoenegocios.com.br/fosfitode-potassio-contribui-para-enchimento-de-graos/\#: :text=Influ\%C3\%AAncia\%20no\%20enchimento\%20de\%20gr\%C3\%A3os\&text=Nesse $\% 20$ contexto\%2C $\%$ 20os \%20fosfitos\%20podem,consequente\%20aumento\%20na\%20produtividade\%20agr\%C3\%ADcola.

Mendes, J. P. P., Amaral, A. M., Verssiani, M. A. S, \& Santos, M. Â. C. M. (2020). Crescimento e qualidade de mudas de baru em resposta a hidroretentor e água magnetizada. Scientia Plena. 16(11), 1-10. https://doi.org/10.14808/sci.plena.2020.110201

Nogueira, R. J. M. C.; Távora, F. J. A. F.; Albuquerque, M. B.; Nascimento, H. H. C.; \& Santos, R. C. Ecofisiologia do amendoim (Arachis hipogaea L.). In O Agronegócio do Amendoim do Brasil. (2013). 2 Ed. Editora Embrapa.

Pereira A. S.; Dorlivete, M. S.; Parreira, F. J.; \& Shitsuka, R. (2018). Metodologia da pesquisa científica. [free e-book]. Santa Maria/RS. Ed. UAB/NTE/UFSM. https://repositorio.ufsm.br/bitstream/handle/1/15824/Lic_Computacao_Metodologia-Pesquisa-Cientifica.pdf?sequence=1

Perin, A. (2001). Desempenho de leguminosas herbáceas perenes com potencial de utilização para cobertura viva e seus efeitos sobre alguns atributos físicos do solo. (Dissertação de Mestrado). Universidade Federal Rural do Rio de Janeiro, Rio de Janeiro, RJ.

Souza, U. O., Santos, L. G., Carvalho, G. B., Santos, A. R. \& Souza, G. S. (2012). Adubação fosfatada e qualidade de luz modificada no desenvolvimento e produtividade da cultura do amendoim. Enciclopédia Biosfera, 8(15), 16-35. https://www.conhecer.org.br/enciclop/2012b/ciencias\%20agrarias/adubacao.pdf

Verssiani, M. A. S.; Amaral, A. M.; Mendes, J. P. P.; Botelho, L. S.; \& Santos, M. Â. C. M. (2021). Influência da irrigação com água magnetizada no cultivo de pimenteiras do gênero Capsicum. Meio Ambiente Brasil (MABRA), 3(5), 064-080. http://meioambientebrasil.com.br/index.php/MABRA/article/view/158 